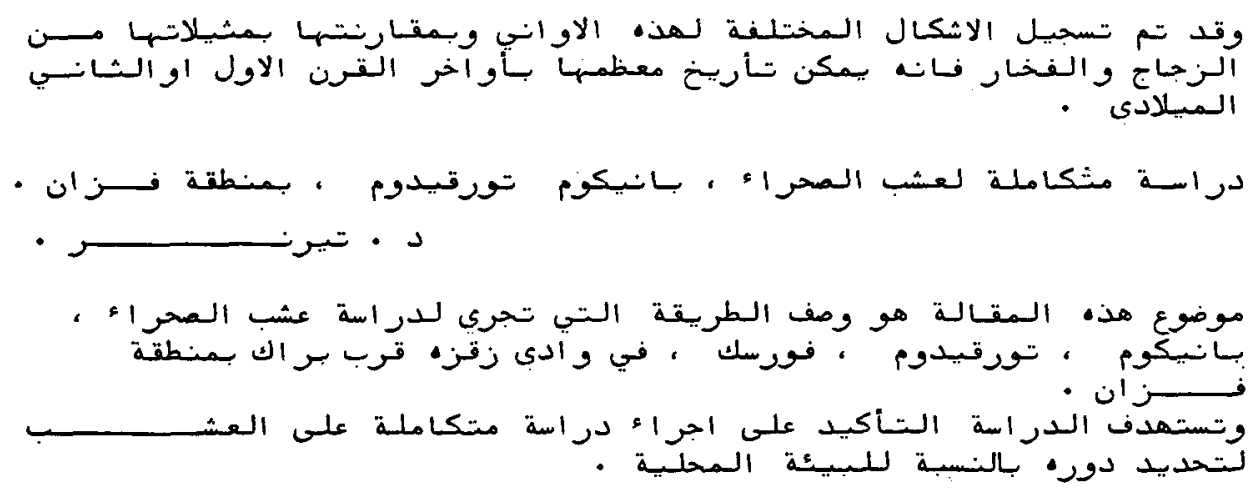




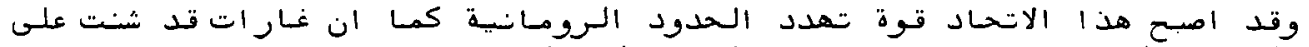

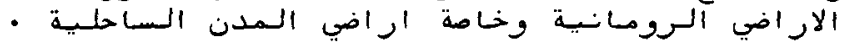

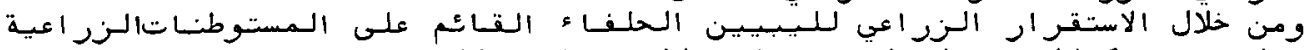

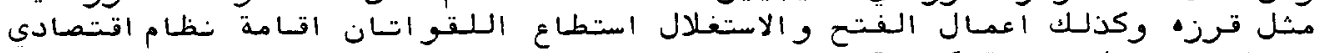

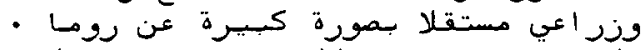

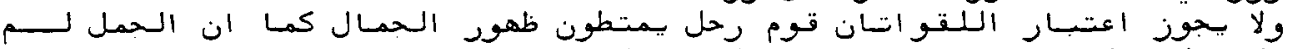

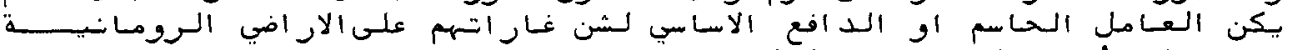

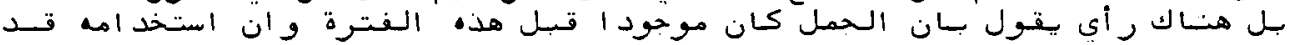

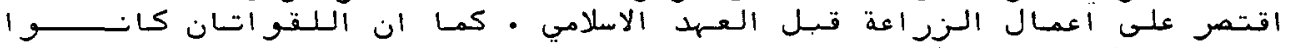

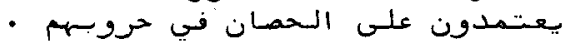

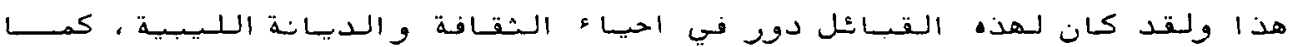

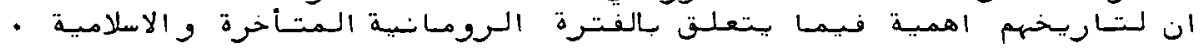

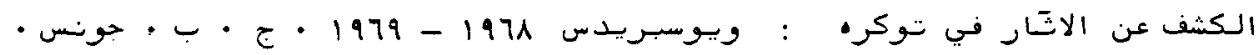

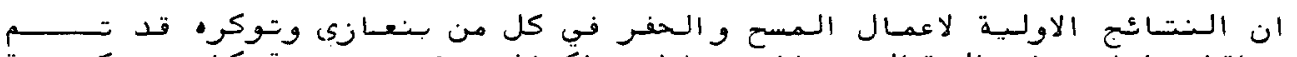

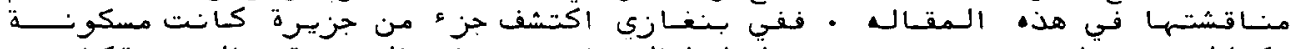

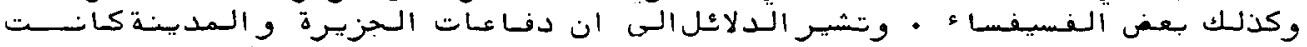

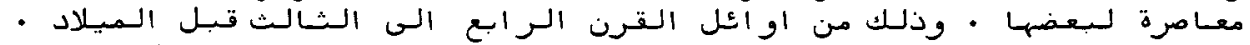

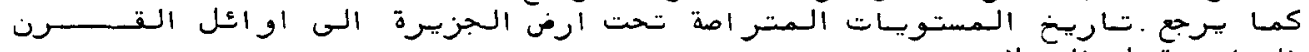

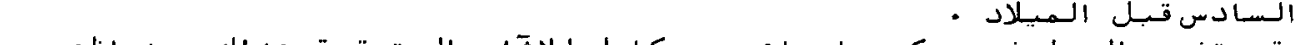

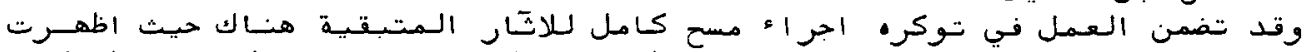

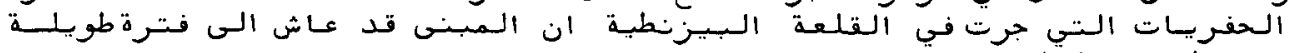

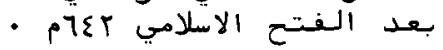

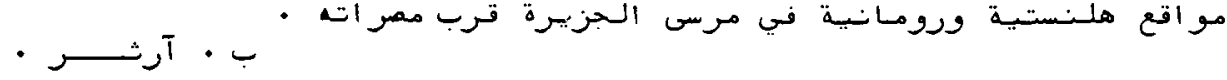

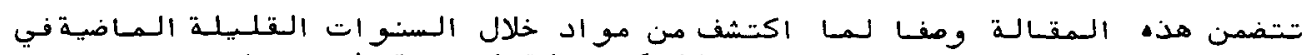

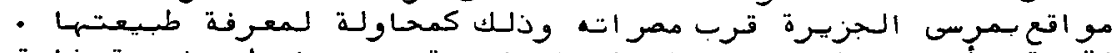

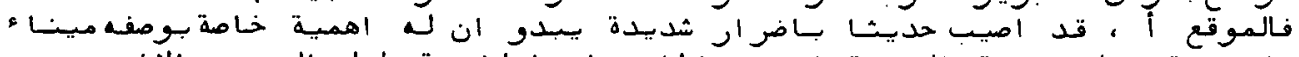

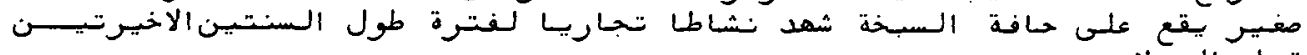
تبل السميلاد علئ

• ج

فخار يرجع الى فترة ماقبل العهد الاسلامي من اجد ابيــ .

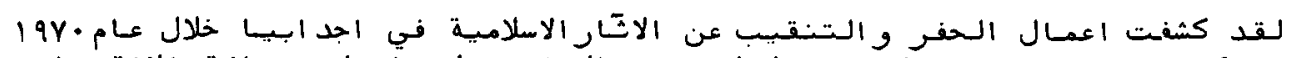

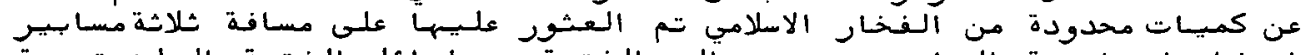

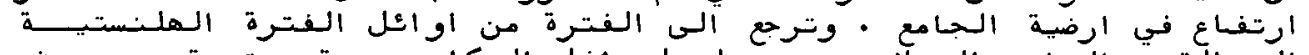

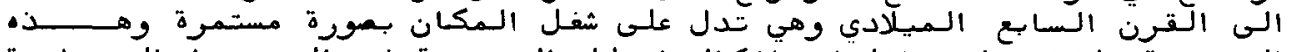

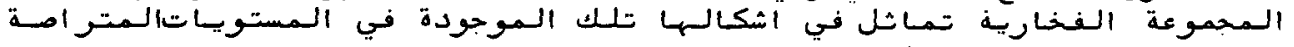

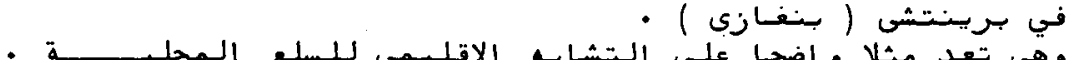

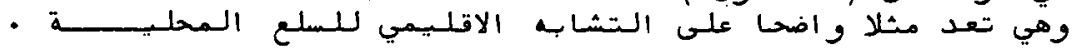
مارلهوت تساقارت الـخزف الرومـني من منطقة جرمة ، ورادي الاجيسال فزان ل

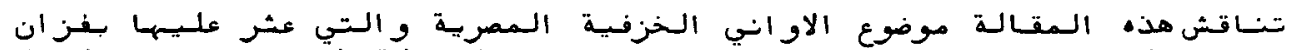

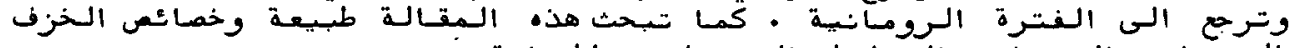

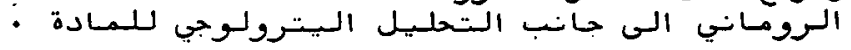

$$
\cdots / \cdots
$$




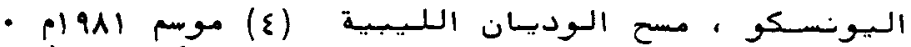

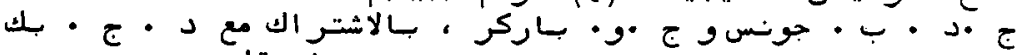

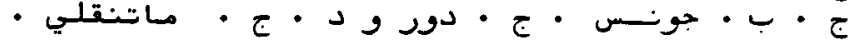

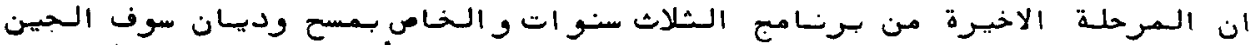

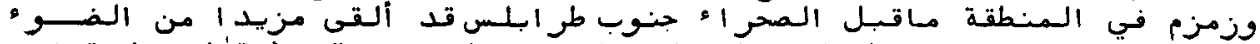

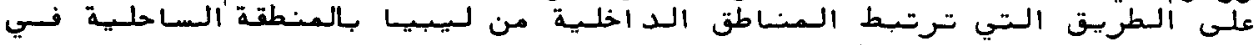

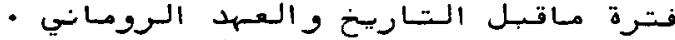

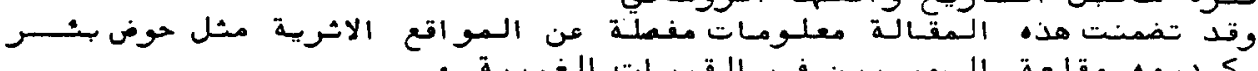

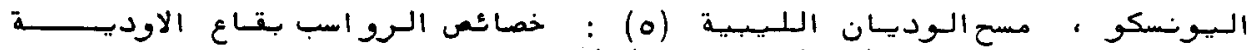

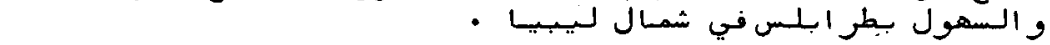

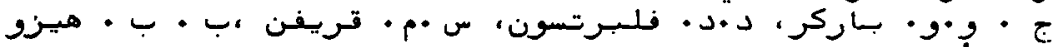

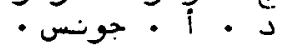

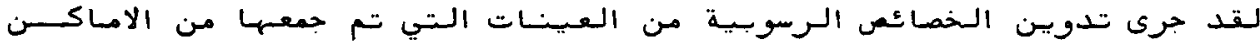

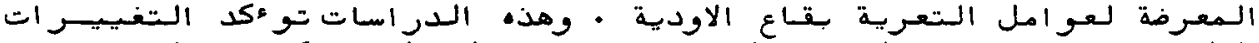

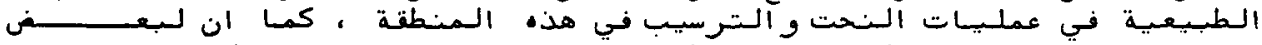

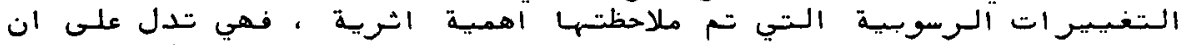

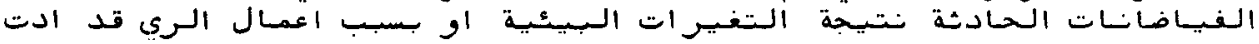

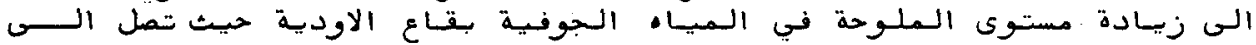

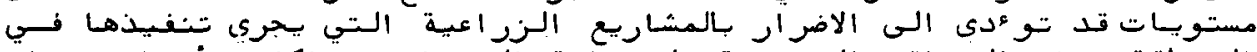

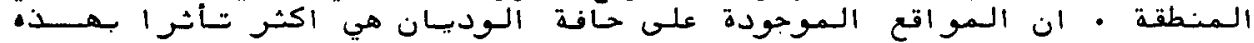

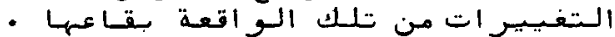

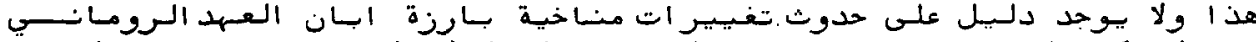

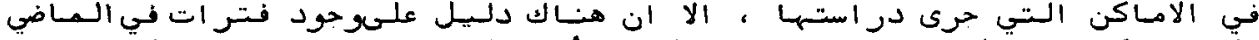

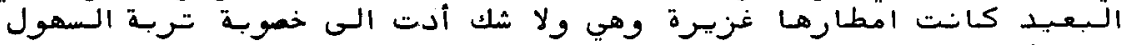

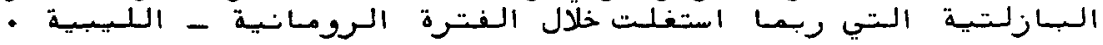

ترجمة خمسة نقوش لاتينية - فيسنيقية من منطقة بـور دريدر - بـولايةطر ابلـس

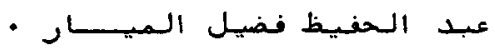

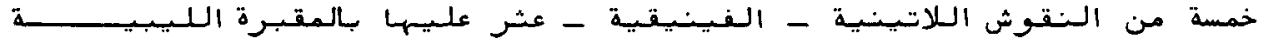

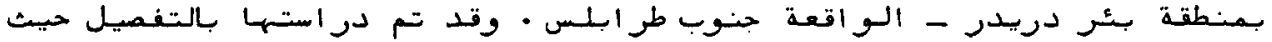

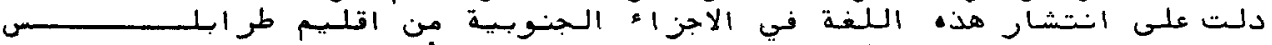

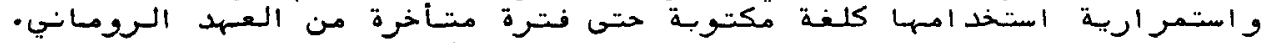

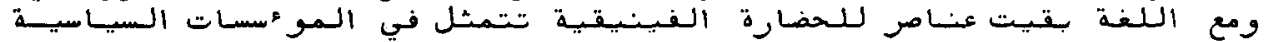

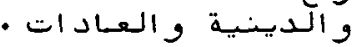

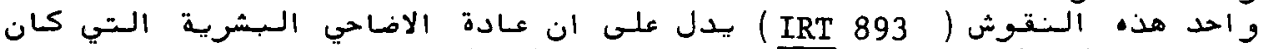

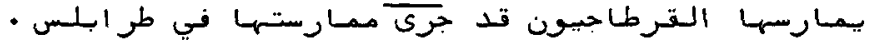

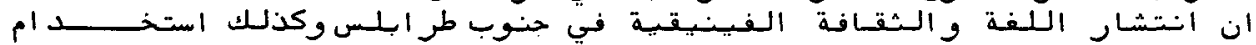

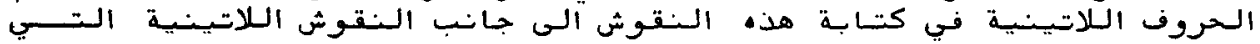

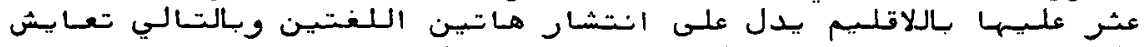

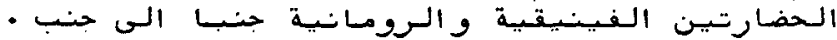

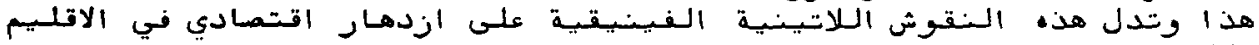

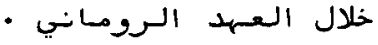

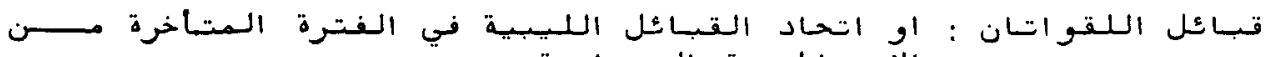

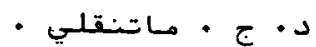

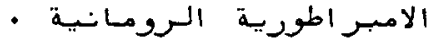

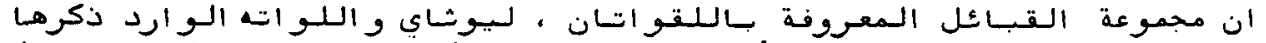

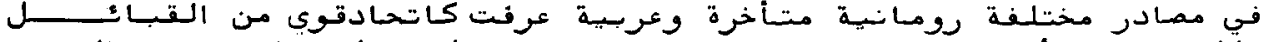

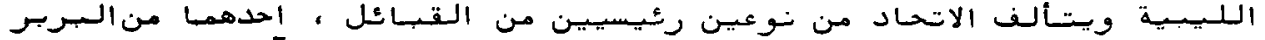

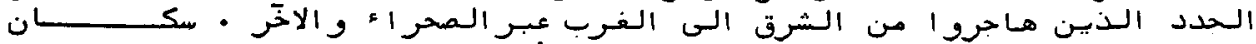

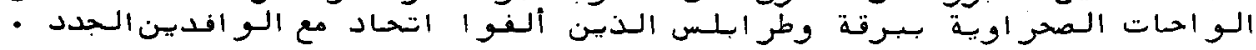




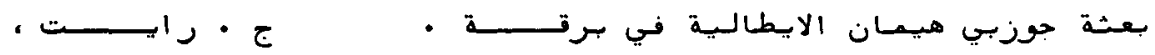

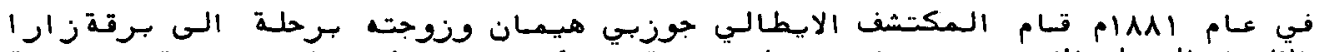

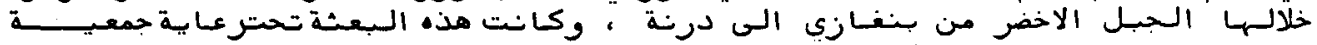

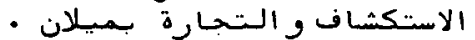

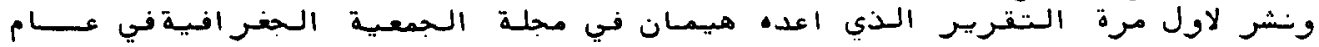

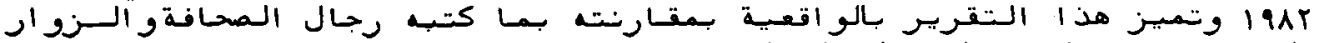

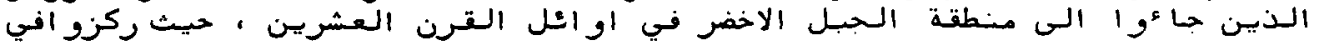

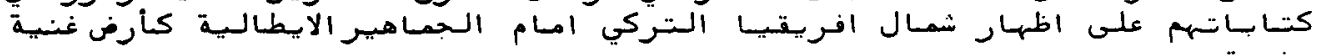

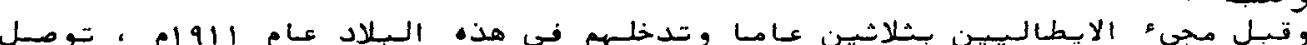

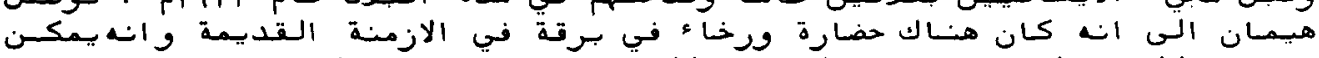

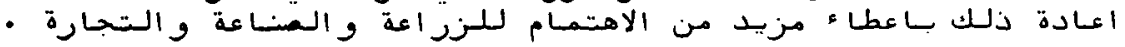

استخد ام الاقمهار الـمناعية في السمسح الاثري • ع .آ.ألن و • م • ريتشارد

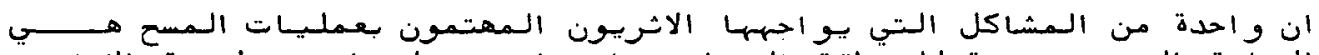

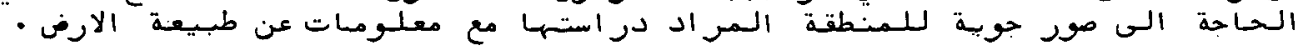

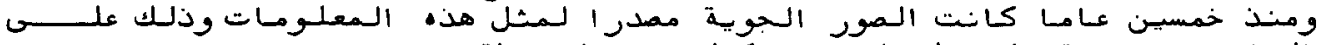

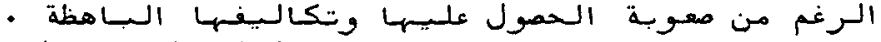

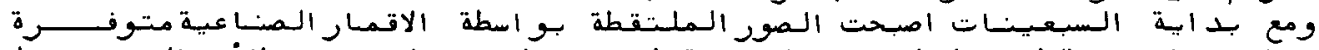

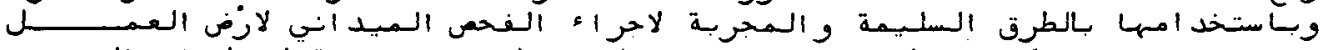

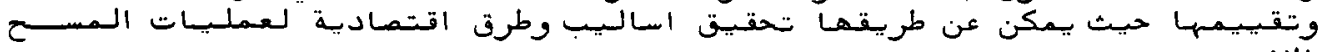

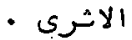

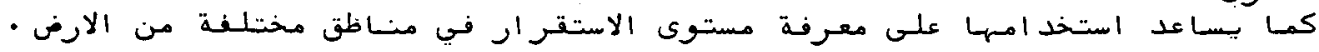

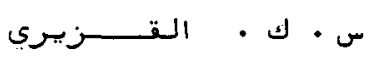

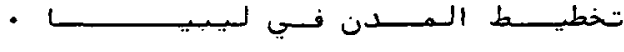

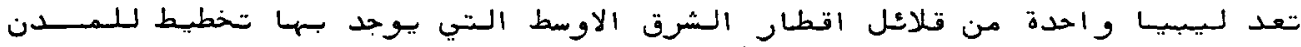

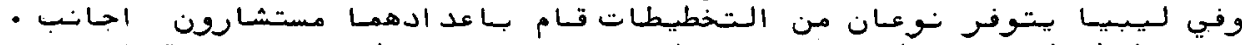

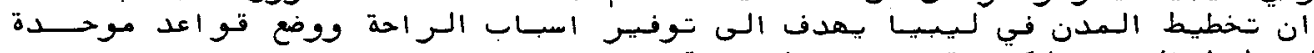

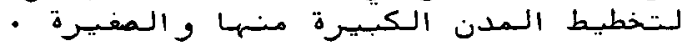

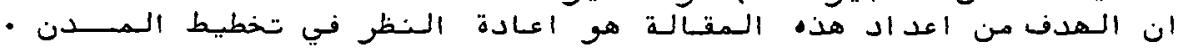

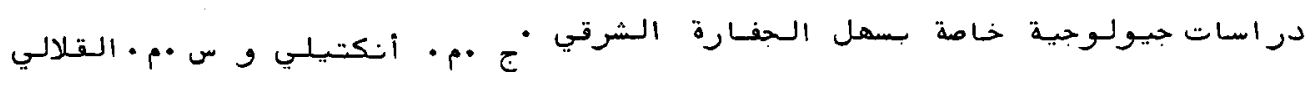

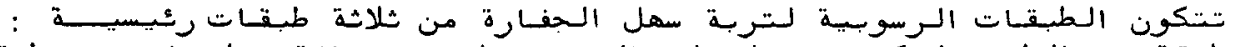

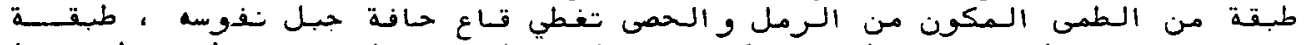

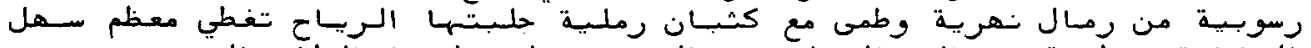

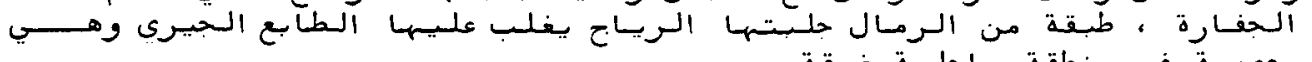

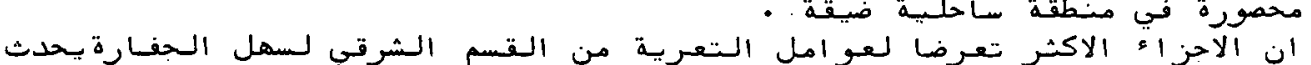

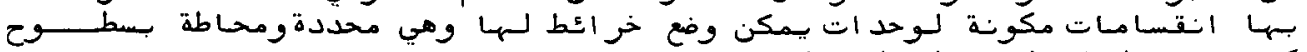

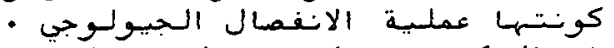

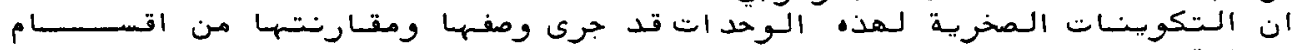

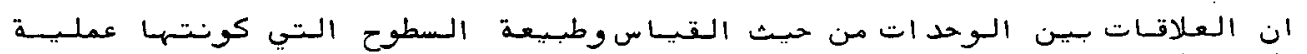

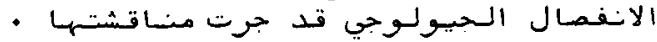

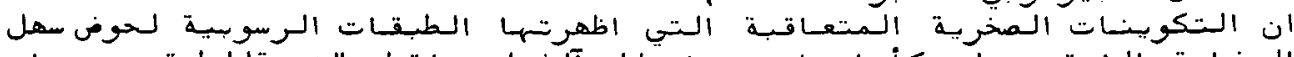

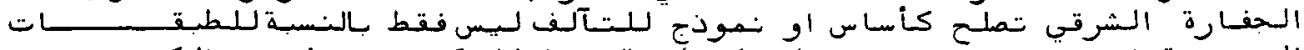

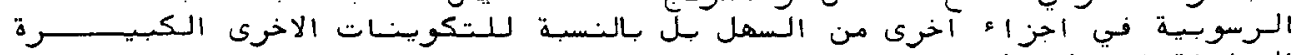

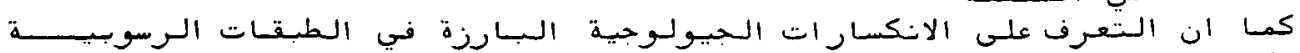

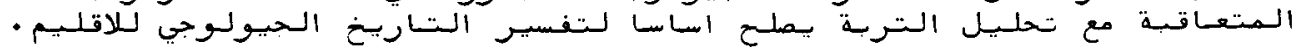




\section{: 1/}

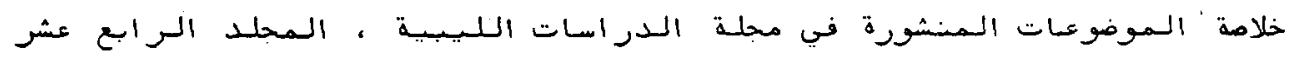
• 194r

$\underbrace{-1} \cdot \tau$

• - 1

4

9

س • • • الـقزيري

16

ج • م • انكتيلي و س •م • السقلالي

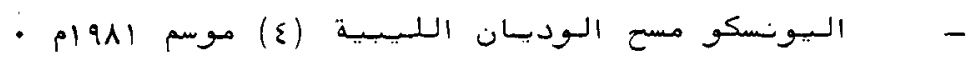

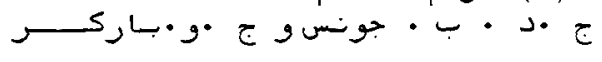

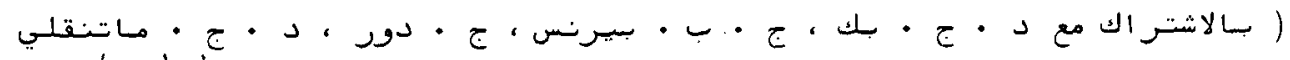

و • (

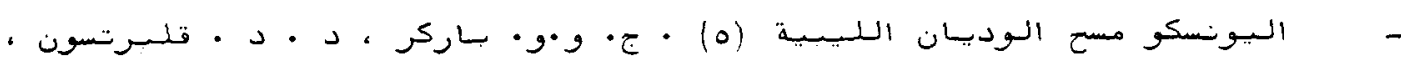

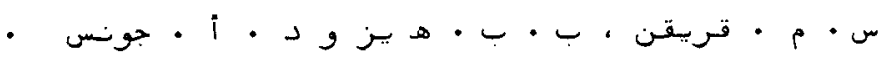

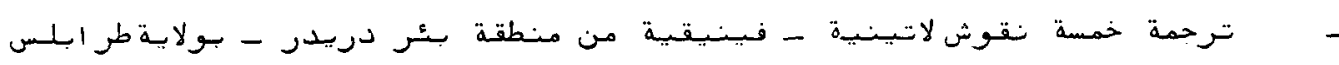

$-86$

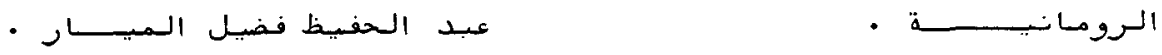

96 - 96

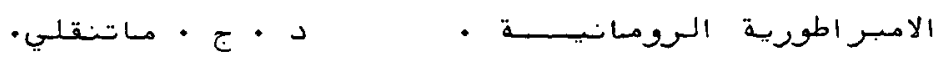

$$
109 \text { - } 1092 \text { - } 138
$$

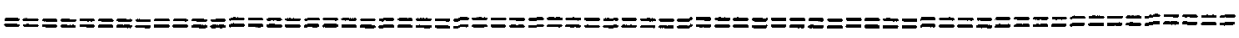




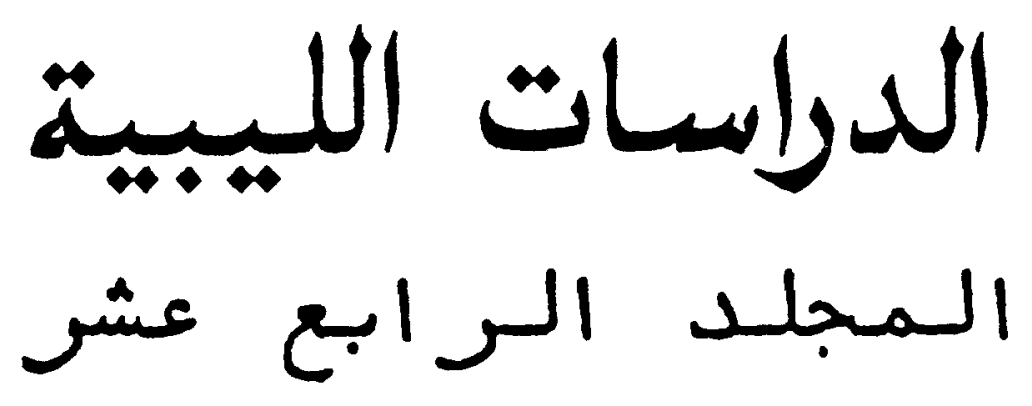

\section{$19 \lambda r$}
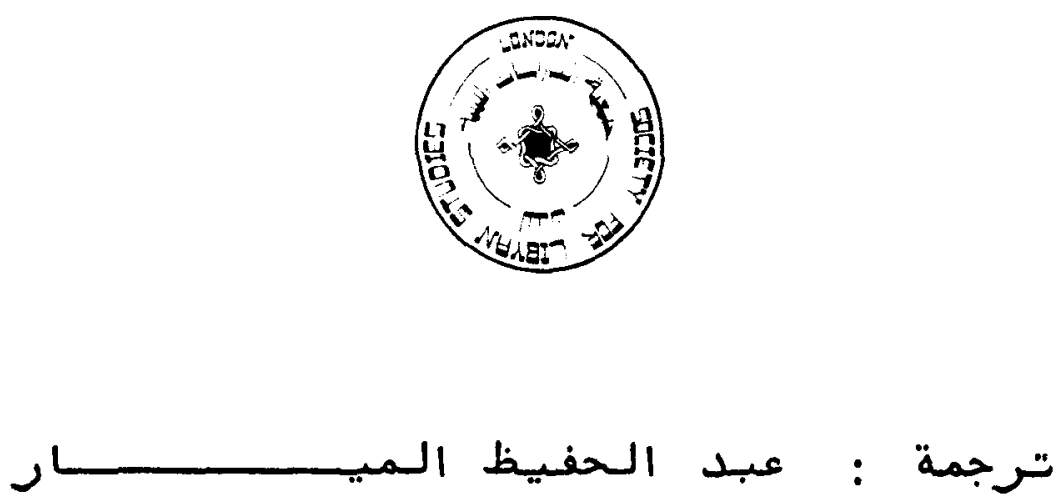

The Society for Libyan Studies 